Article

\title{
Advocating for Platform Data Access: Challenges and Opportunities for Academics Seeking Policy Change
}

\author{
Katharine Dommett ${ }^{1, *}$ and Rebekah Tromble ${ }^{2,3}$ \\ ${ }^{1}$ Department of Politics, University of Sheffield, UK \\ 2 School of Media \& Public Affairs, George Washington University, USA \\ 3 Institute for Data, Democracy \& Politics, George Washington University, USA \\ * Corresponding author (k.dommett@sheffield.ac.uk)
}

Submitted: 16 July 2021 | Accepted: 1 November 2021 | Published: 17 February 2022

\begin{abstract}
Independent researchers' access to digital platform data is critical for our understanding of the online world; yet recent reflections have shown that data are not always readily available (Asbjørn Møller \& Bechmann, 2019; Bruns, 2018; Tromble, 2021). In the face of platform power to determine data accessibility, academics can often feel powerless, but opportunities and openings can emerge for scholars to shape practice. In this article, we examine the potential for academics to engage with non-academic audiences in debates around increased data access. Adopting an autoethnographic approach, we draw on our personal experiences working with policymakers and digital platforms to offer advice for academics seeking to shape debates and advocate for change. Presenting vignettes that detail our experiences and drawing on existing scholarship on how to engage with non-academic audiences, we outline the opportunities and challenges in this kind of engagement with a view to guiding other scholars interested in engaging in this space.
\end{abstract}

\section{Keywords}

advocacy; data access; non-academic engagement; platforms; policymakers

\section{Issue}

This article is part of the issue "Analyzing Citizen Engagement With European Politics Through Social Media" edited by Pieter de Wilde (Norwegian University of Science and Technology), Astrid Rasch (Norwegian University of Science and Technology), and Michael Bossetta (Lund University).

(C) 2022 by the author(s); licensee Cogitatio (Lisbon, Portugal). This article is licensed under a Creative Commons Attribution 4.0 International License (CC BY).

\section{Introduction}

Whether studying the impact of digital technology on the world of work, political speech, public health, news consumption, elections, cartography, or much besides, scholars from a range of disciplines require access to data about people's online activities and interactions. However, these data can be exceedingly difficult, if not impossible, to obtain. The private companies that dominate the digital landscape-collecting terabytes of data about their users' behaviours and preferences-have been reluctant to share these data with independent, external researchers. Though some of these companies have occasionally shown willingness to share some data with scholars, the types and applications of such data have been limited, and scholars remain reliant on the goodwill of the platforms to provide data when and how they see fit (Asbjørn Møller \& Bechmann, 2019; Bruns, 2018; Tromble, 2021). Against this backdrop, a variety of academics, civil society researchers, journalists, and policymakers have called for improved access to platform data, but less attention has been paid to the role academics can play in bringing about such change.

In this article, we explore the potential for academics to shape debates and actions related to data access. Drawing on our personal experiences engaging in this area, we argue that, far from being passive actors subject to the whims of companies and policymakers, academics 
around the world can play an important role in securing better data access and helping to ensure greater platform accountability. Inspired by the auto-ethnographic tradition of academic scholarship, we combine a review of the existing literature on knowledge exchange and achieving "academic impact" with our own experiences of engaging with non-academic communities to consider the opportunities and challenges scholars can face. Our aim is to cast light on the challenges encountered in this space and to provide scholars with the knowledge required to continue this important work. Whilst our experiences point to positive developments in bringing about change, we argue that academics need to understand more clearly the particularities of working with companies and policymakers to engender change in this space. As the internet continues to rapidly evolve and pose new challenges for academic research, this skill set will become increasingly valuable.

We begin with an overview of the debate around data access, before discussing our autoethnographic methodology and then turning to our personal experiences. We combine short vignettes detailing our experiences with key insights from the existing literature on knowledge exchange. Using this approach, we highlight the opportunities and challenges of non-academic engagement and reflect on the lessons our experiences offer others. We end by offering advice for scholars who wish to engage in public-facing policy work related to data access and beyond.

\section{Data Access}

When it comes to determining precisely what impact technology has had on society, researchers are constrained by issues of data access. Dominated by private companies, a range of information now lies in the hands of corporations that are under no obligation to facilitate independent research (Algorithm Watch, 2020, p. 5). Whilst a longstanding challenge for scholars interested in digital technology, in recent years the situation has arguably gotten worse, as companies have further restricted data availability. Most notably, this occurred in the wake of the Cambridge Analytica controversy when, in 2018, social media platforms restricted access to data via their application programming interfaces (APIs). This "APIcalyse" (Bruns, 2019) significantly curtailed the availability of data for analysis (Freelon, 2018, p. 665). Indeed, reviewing data availability for key platforms, Asbjørn Møller and Bechmann (2019, p. 2) conclude that "the methods for data exchange provided by the social media platforms are subject to increasingly strict restrictions of data access, making it difficult-if not impossible-to extract substantial social media data for thorough investigations."

Since these developments, certain avenues for academic research have begun to open (Tromble, 2021, p. 3). Individual companies have taken steps to provide datasets for academic researchers, with some compa- nies providing curated sets of publicly available data in online archives (such as the advertising archives offered by Facebook, Google, and Snapchat [Edelson et al., 2018]), and others working with specific researchers (e.g., Vosoughi et al., 2018). Academics have also been working with platforms to broker access to specific datasets, most notably through the Social Science One initiative (King \& Persily, 2018, 2020). These developments are to be welcomed, and yet they are limited. There remains a huge amount of data about the digital world that is not available for scrutiny, meaning, as Persily has argued, that "we do not know even what we do not know concerning a host of pathologies attributed to social media and digital communication technologies" (2021, p. 1).

In proposing a response to this situation, academics have begun to outline a range of options. Bruns (2019), for example, has argued that academics can either give up, lobby for change, accommodate and acquiesce, or break the rules to gain access to data. Within this article, our interest is in the potential for academics to play an active role in shaping debates, including by "lobbying" or "advocating" for a specific outcome (Pielke, 2007, pp. 2-3; see also Perriam et al., 2020, p. 279). Heeding Puschmann's call for the research community to "engage constructively with all stakeholders, including internet companies, but also with regulators and political actors, in order to improve the current situation" (2019, p. 1583), we are interested in how academics can engage to alter the status quo.

Considering the case of increased data access, it is worth clarifying that, as individuals, we do not uncritically assume that unfettered data access is good, or even necessary. Rather, we are interested in how academics can participate in nuanced discussions about when and how researchers might responsibly attain access to data in service of the broader public good (Tromble, 2021). Whilst this kind of advocacy is gaining increased interest from the academic community, to date, there has been little discussion of what engagement in the policy realm involves for academics, and specifically about the nature and risks of such activity. For this reason, within this article, we offer an auto-ethnographic account of our own experiences and draw on existing literature on knowledge exchange and achieving "academic impact" to offer advice for scholars considering this form of activity.

\section{The Autoethnographic Approach}

The autoethnographic approach seeks "to describe and systematically analyze (graphy) personal experience (auto) in order to understand cultural experience (ethno)" (Ellis et al., 2011, p. 273). The methodology relies on the "writing of self-narratives" to provide "a window through which self and others can be understood" (Chang, 2016, p. 13). One's positionality is particularly important within autoethnography. As Ellis et al. (2011) note, "when researchers do autoethnography, 
they retrospectively and selectively write about epiphanies that stem from, or are made possible by, being part of a culture and/or by possessing a particular cultural identity" (p. 276).

To be sure, the experiences we describe herein have been informed and shaped by both structural factors and personal idiosyncrasies, and we certainly do not make any claims to universality. We are both white, middle-class scholars, employed by well-respected academic institutions. These factors allowed us to enter policy and industry spaces with a degree of presumed credibility. We are also both political scientists, which provided us with a baseline understanding of how political institutions operate and how we might navigate within them. (Though we certainly were naïve in many ways that we learned along the way.) But perhaps most importantly, we both have the professional security provided by tenure. While we were unlikely to gain institutional reward for engaging in advocacy work, our careers were never on the line.

At the same time, as women, policy and industry spaces-each heavily imbued with patriarchal norms and misogyny-were often profoundly uncomfortable and difficult to traverse. As we discuss in greater detail below, all too often, we found ourselves upstaged and crowded out by men with less knowledge and expertise. What is more, at the time we began this work, neither of us was especially well-known in our fields, and though our institutions were well-regarded, they were not among the most elite. Indeed, in the early days, neither of us could call on influential contacts to help open doors. For each of us, these circumstances led to many frustrations, and at times left us questioning whether we should forge ahead.

Recognizing intersectional privileges and structural constraints is a key part of the autoethnographic approach (McKay, 2021, p. 89). However, we should note that we did not enter advocacy work with the intention of making our experiences the subject of study and analysis. We were undertaking work in support of our research but not as an object of research, per se. In other words, we did not see ourselves at the time as (auto)ethnographers. And thus, we did not undertake many of the careful, systematic techniques typical of (auto)ethnography (see Chang, 2016). We did not, for example, consider those with whom we interacted to be research subjects. They only became so retrospectively. And, as such-beyond the clarification of ground rules for reporting on meetings and other interactions (e.g., via non-disclosure agreements or the application of Chatham House Rules)-we did not obtain consent from our interlocutors. This naturally raises ethical concerns (Delamont, 2009, p. 59; Ellis et al., 2011, p. 281). We have therefore followed McKay (2021, p. 90) in choosing to avoid presenting much detail and specificity in the vignettes we offer below. This choice necessarily inhibits the analytical richness typical of autoethnographic accounts, and yet we believe our cho- sen vignettes still enable us to tell " 'pointed truths' that have the potential for creating change and envisioning ways forward" (McKay, 2021, p. 89).

It should also be noted that, contrary to the expectations of "autoethnography as methodology" (Chang, 2016), we did not take methodical field notes. However, in many instances, we did take meeting notes or contemporaneously record reflections and items to remember after interactions with policymakers, platform representatives, and other researchers. We also have extensive documentation in the form of emails, collaborative documents, and reports we have authored, and this rich record has allowed us to recall significant thoughts, frustrations, reflections, and insights-i.e., key "epiphanies" (Ellis et al., 2011)-from several years' worth of work. We reviewed these documents in identifying and compiling our vignettes to ensure their robustness; yet we wish to make clear that our records are imperfect, our memories flawed, and the reflections we offer here are undoubtedly coloured by survivorship bias.

We share our reflections here because, while advocacy work among academics is still rare, we believe it is growing in importance. Though some pockets of academia have remained relatively insular-speaking primarily, if not exclusively, to other academics - that position is growing increasingly untenable for many. Public officials, external funders, and university administrators alike are calling on academics to ensure our work reaches the public. This in turn means that ever-growing numbers of scholars find themselves treading into unfamiliar spaces, engaging with policymakers and practitioners in contexts that seem foreign and at times possibly even uncomfortable. Thus, though personal, the vignettes we offer in the following section relate our experiences to themes within existing academic literature on knowledge exchange and achieving "academic impact" (Boswell \& Smith, 2017; Dunleavy \& Tinker, 2020; Pielke, 2007).

\section{Our Autoethnographic Experiences}

To preface our analysis, some broad context about our respective roles is necessary. Rebekah has been working with technology companies, politicians, and academics in the USA and Europe since 2018, notably advising policymakers developing legislation within the EU and USA. She leads an international, interdisciplinary team of independent researchers selected by Twitter after an open request for proposals to study the "health of conversations" on the platform. She was also a member of the European Advisory Committee of Social Science One, and she serves as chair of the European Digital Media Observatory working group that has brought together academic, industry, and civil society representatives to develop a Code of Conduct for data access under the EU's General Data Protection Regulation. These experiences have led her to build extensive relationships with academics, civil society representatives, policymakers, and tech company staff. 
Katharine's engagement is more recent and focuses primarily on the UK and European policy debates. Specifically, she served as special advisor to the House of Lords Committee on Democracy and Digital Technology in 2019-2020 and in this role worked with policymakers to write background notes, draft questions, identify witnesses and contribute to the final committee report. She has also engaged with the European Commission around the new Digital Services Act, as well as numerous parliamentary inquiries in the UK. At present, she serves on the European Digital Media Observatory's working group on access to platform data.

We both have first-hand experience reaching beyond academia and engaging with non-academic audiences and have witnessed these efforts begin to bear fruit. We have also observed the processes through which policy recommendations are developed and company policies and practices are updated and evolve. In the next section, we draw on this knowledge and, by reflecting on the personal and systemic factors that have conditioned our experiences and relating these to existing literature, distil lessons and offer advice for other scholars seeking to engage in similar work.

\section{Advocating for Platform Data Access: Two Key Insights}

Our reflections focus on two aspects of policy and advocacy work that we believe are particularly important. These are: gaining access and confronting professional barriers. Each theme is discussed below in turn.

\subsection{Gaining Access}

Our first theme focuses on the challenges of gaining access to non-academic arenas. Within existing scholarship on non-academic engagement, it can appear that external audiences are eagerly awaiting academic insights. Offering an often idealized and linear account of academic engagement, scholars are encouraged to conduct research and then communicate it to wider society to inform real-world practices (Weiss, 1979, p. 427). Advice often focuses on how to communicate clearly and effectively (Farmer, 2010; Oliver \& Cairney, 2019, p. 3), but there is rarely much discussion of who the audience for this information is, and where communication should be targeted.

These questions are particularly important for a topic like data access, because non-academic engagement is likely to require interaction with a range of actors - from policymakers to civil society organizations, tech companies to journalists, and the public at-large. Gaining the attention of each of these actors is not straightforward, as each has their own set of incentives driving their interest and willingness to engage. Accordingly, we use our vignettes to interrogate our experience of engaging with the two sets of actors who have proven most pivotal to progress on the issue of data access: policymakers and tech company representatives. Comparing our experiences, we reflect on the personal and structural factors that have affected our engagement and consider what this means for others attempting to secure access in these arenas.

\subsection{Vignette 1: Katharine's Experience}

With policymakers, I have had the most success gaining access and have been able to exercise the most control over the process. This capacity evolved over time and with professional support, as initially I had little knowledge of how policymaking forums worked, and in my first few encounters I felt deeply intimidated and illequipped to contribute. At the start of my career, I was, however, fortunate enough to have a mentor who introduced me to the array of Parliamentary inquiries, consultations, roundtable discussions, and closed-door meetings that occur in the UK. Proactively building on this advice, I familiarized myself with these forums and gradually grew to understand the rules of engagement.

When my research started to move up the political agenda, this familiarity proved invaluable. I not only understood where to look for relevant opportunities to engage, but also what kind of information they wanted. I was also aware of the incentives that drove policymakers' interactions with academics, knowing that the UK Parliament had committed to diversifying its source of expertise (beyond the usual male suspects from London universities). I was able to use this knowledge to my advantage and began to contact those responsible for new inquiries in my areas of interest-an approach that led me to be appointed as a special advisor.

My access to policymakers, therefore, reflected the investment I was able to make in gaining an understanding of and familiarity with these institutions - an investment supported by colleagues and my university. It also reflected my accommodation to systemic factors, as I was willing to work within the existing system towards incremental change, and to adapt to hierarchical and often patriarchal norms of parliamentary engagement. Many other scholars may be unable or unwilling to make such accommodations.

My experience with companies, on the other hand, could not have been more different. Whilst I was able to cultivate an understanding of the policymaking world, I had little understanding of tech companies, no existing relationships with them, and few means of accessing support to cultivate relationships. My attempts to engage company staff at public events were often greeted dismissively. Epitomized by a conversation at a workshop at the European Commission, an employee from Facebook responded to my request for a business card by saying that the company did not use them. Two minutes later, I looked across the room to see the same employee pass a business card to a high-profile attendee from another social media company. This experience was indicative of the lack of value I apparently had to companies- 
something I felt powerless to change. The degree to which tech companies themselves were determining my apparent value became particularly evident when I was appointed special advisor to the House of Lords inquiry. Finally, I began receiving responses to my emails, and I was invited to Facebook headquarters in London to discuss my research and explore areas of mutual interest. This influence was, however, short-lived. As soon as my tenure with the Lords ended, so did Facebook's responsiveness. Whilst I, therefore, found I had some degree of control over my access, there were wider structural and cultural factors at play that I had little ability to control.

\subsection{Vignette 2: Rebekah's Experience}

Unlike Katharine, my early career training did not provide opportunities to witness or work within policy circles, and my initial failures reflected my resulting naivete. Based in the Netherlands, when I began working on the issue of data access, I first focused on attending highprofile policy events in Brussels. Though I met many interesting people along the way, these events rarely proved fruitful. There were simply too many people-all clamouring for attention and recognition. In these large, open settings, institutional power dynamics were particularly evident. Titles and affiliations were currency, and on several occasions, I found my arguments pushed aside, only to be taken up again when influential men echoed them. I often doubted whether I would ever belong or be heard in these spaces.

Yet, over time, I did begin to feel like I belonged. I was eventually heard. And I attribute this shift to two intentional, strategic changes I made. First, I began looking for smaller, lower-stakes opportunities to engage with policymakers. Indeed, my "big break," as it were, came when I attended a small disinformation workshop in Milan. I was not an invited speaker or panellist; I was merely an attendee, welcomed by a former student who knew I was interested in the topic. But with fewer than 100 people gathered-and situated well away from the traditional centres of European political power-the workshop was more relaxed. Credentials and status mattered much less, and there was less jockeying for attention. About midway through the workshop, during a panel Q\&A session, someone in the audience asked a question about the latest news from Social Science One. Was the initiative making any progress in attaining data access from Facebook? The question was addressed to the panellists, but, as it turned out, I was the only one in the room directly involved in the initiative. I wound up fielding the question, as well as follow-ups, and at the next break, two policy staffers and several researchers working closely with officials at the European Commission approached me and asked if I would be willing to take some meetings. Within the next month, I had spoken with officials and key members of their staff in France, the Netherlands, Germany, and Brussels.
These opportunities arose because of the structures of political and intellectual power within which I was embedded. When I began venturing into the policy arena, I lacked political capital. I was not a star in my field. My name and title meant little to my intended audience. I wielded a baseline level of acknowledged credibility, but this afforded me little advantage when sharing space, and competing for recognition, with academic "superstars" from the most elite institutions. At the smaller, less prestigious Milan event, however, my specialized knowledge and expertise permitted a critical breakthrough moment. I was in the right place at the right time. But the place and time were right precisely because the political stakes were significantly lower, and my expertise could stand on its own.

Once I had my foot in the door, I implemented my second strategy shift-carefully reshaping my style of communication with policymakers and their staff to help ensure that my expertise would be recognized, valued, and called on again. Namely, I worked to tie the issue I cared about so much-data access - to the issues at the top of policymakers' agendas and to do so in highly illustrative ways (i.e., usually supported by colourful examples or a simple but rich narrative story). There were natural links to topics like disinformation, political polarization, civil rights, etc., but in the early days, I arrived at those large, high-pressure events unprepared and ill-equipped to communicate those links. Yet, once I began securing closed-door meetings with policymakers, I quickly learned that demonstrated expertise, communicated clearly and vividly, is of the utmost importance.

This, too, I view through the lens of structural power. Initially lacking the weight of institutional prestige and the authority of masculine voice, I was able to gain and maintain my standing in these political spaces by serving as translator and storyteller-simplifying complex issues and articulating them through vivid narratives that captured and held attention.

This bridging, storytelling role has proven essential to gaining access to the platforms as well. Put bluntly, the leaders of Silicon Valley corporations generally want to deal with-and in many cases, co-opt-people they believe have significant influence. That usually translates to a preference for working with and providing access to academics at elite universities, those who publish in top journals, and those who garner significant media attention. USA academics at Ivy League institutions are usually preferred, and members of the platforms' communications and policy teams-those most likely to be interested in prestige and influence-typically act as company gatekeepers.

However, each of these companies also has teams of engineers and researchers whose interests are wellaligned with independent scholars. Because engineers and researchers are focused day-to-day on building better products, tools, and systems, they have good reason to seek out and even collaborate with academics. I found some of my greatest allies within these companies while 
attending conferences or lectures, and after talking to many about mutual research interests, began to be invited to informally consult and help think through common problems and ideas. Through these interactions, I began to understand much more clearly how the companies operate, including what incentives different actors inside the companies possess. That knowledge has helped me become a much more effective advocate for data access. When speaking with policymakers now, I can explain different aspects of the problem and reflect thoughtfully about potential solutions-not just from the academic perspective, but also realistically assessing arguments offered by the tech companies. In other words, I can help policymakers more effectively filter and interpret corporate talking points, separating cynical spin from the arguments offered in good faith and with merit. This influence with policymakers, in turn, opens more doors within the companies, creating an access feedback loop that has proven crucial in overcoming my own lack of superstar, Ivy League credentials. If I continue to engage with policymakers, the platforms will continue to engage with me.

In short, power begets access. However, in this case, the route to power was paved by the professional spaces I share with tech company researchers. The type of research I conduct-namely, computational social science-places me in dialogue (literal and figurative) with company researchers. We publish in similar venues, regularly cite one another's work. We speak a common research "language." These shared cultural understandings-unavailable to many other academics - have been the key to building relationships that, in turn, increased my understanding of, and furthered my access to, the companies themselves.

\subsection{Reflections on the Vignettes}

These two vignettes suggest that gaining access to policymakers and companies is not always straightforward and is conditioned by a range of personal and structural factors that can enable or constrain access. At our most successful, we have been supported either by mentors or institutional configurations (e.g., tenure) that have enabled, if not necessarily always encouraged, our investment in these spaces, and we have both been willing to adapt in the face of varying cultures of engagement. These opportunities will not be open to all scholars, and hence we do not suggest that all academics should seek to engage in this kind of work. Access is often difficult, requiring sustained personal investment that poses personal and/or professional trade-offs and risks that are simply too high.

For those who are willing and able to engage in this kind of work, our vignettes suggest that certain strategies can pay dividends. Both of our experiences demonstrate the value of a proactive, creative approach that involves familiarising yourself with your chosen institution and audience and their needs, attending events, and deter- mining the unique contributions you can offer. This conclusion aligns with advice within the existing literature on knowledge exchange, which suggests that scholars should "get to know how policy works," "[b]e accessible" to policymakers through routine engagement (Oliver \& Cairney, 2019, p. 3), and develop a shared understanding (Lomas, 2000). And yet, our vignettes also show that the payoff is far from guaranteed. One may be present, prepared, and available and still never attain real access. In part, this is because of different institutional cultures. Policymaking environments often actively look for new perspectives and, at times, unfamiliar voices, but this is not the case with tech companies. Indeed, we have both seen first-hand that reputation and influence are essential to these companies. And though alternative routes may be available-especially if one operates within shared cultural spaces with company employeesthe amount of time and energy required to cultivate access may prove daunting. A degree of personal reflection is therefore required to determine where it is best to target your efforts. One might, for example, map existing and potential points of contact and connection, thinking not just about the people you already know, but about what lower-stakes opportunities might be available to forge new contacts. Consider whom among your intended audience is most likely to speak a shared language and understand your perspective, and use interest alignment and common perspectives as a starting point.

\subsection{Confronting Professional Barriers}

The second theme we explore is the question of professional barriers to engagement. Within the literature on non-academic engagement, a rich strand of reflection and critique demonstrates just how high these barriers remain. Concerns have been raised about the time and resources required, the risk of burnout (Graffy, 1999), and the challenge of juggling engagement alongside the many other pressures of academia (Khan et al., 2019). Attention has also been paid to the professional costs and benefits of this activity, recognizing that this work is not uniformly valued. As Farmer has argued, "[a]cademics generally do not receive much credit from their institutions for providing information to policymakers, unless their efforts result in funding" (2010, p. 717), with Watermeyer (2015) finding that public engagement work rarely contributes towards promotion. Even where demonstrating "impact" is valued by academic institutions, existing research suggests that scholars' ability to deliver tangible outcomes is by no means guaranteed. Indeed, Cairney and Oliver (2020) highlight that an investment of time may pay off only after years or decades, creating uncertain returns for scholars engaging in this kind of work. There are also acknowledged reputational risks, with scholars often judged by peers to be "lightweight" because they engage non-academic audiences (Maynard, 2015).

In addition, systemic barriers operate unevenly. As Oliver and Cairney highlight, engagement is often 
more difficult for "more junior or untenured researchers" $(2019$, p. 6), arguing elsewhere that "white men," who "are more likely to be in senior academic positions, published and cited in high 'impact' journals" are more likely to have the resources and profile to be able to engage (Cairney \& Oliver, 2020, p. 237; see also Geddes, 2018). Relatedly, even if managing to take opportunities, research shows that "women and people of colour may be more subject to personal abuse or exploitation" (Oliver \& Cairney, 2019, p. 6), creating uneven consequences of public engagement. Beyond these factors, certain kinds of knowledge are more likely to gain an audience than others. Indeed, academics advancing criticism, marginal perspectives, or politically incongruous messages can gain less traction for their ideas amongst stakeholders (Wright et al., 2007). Building on this, we argue that it is vital for academics to cultivate professional and personal support.

\subsection{Vignette 3: Rebekah's Experience}

I have experienced the difficulties of pursuing policyoriented work in two very different academic environments: Leiden University and George Washington University (GW), respectively. When I first took a position at Leiden University, policy work did not cross my mind. Though many senior male colleagues served as consultants to government agencies and one colleague was a political party leader, for junior scholars, there simply was no career benefit. We were evaluated based on teaching and research output, with emphasis on the latter. A few years later, universities in the Netherlands began to pay more attention to so-called "valorisation," and our media citations and other forms of public outreach began factoring into annual reports. However, valorisation was treated more as a sweetener on top of our staple diet of teaching and research than a core component of our work. It looked good for the university but had little to no impact on promotion and other forms of career advancement. In fact, in some cases, high levels of public engagement were considered a detriment. Egalitarianism is highly valued in Dutch culture, and activities that could be interpreted as individualistic, especially if considered "showy" or "attention-seeking," were actively frowned upon by many colleagues. Thus, the path of least resistance was preferable, especially before tenure. However, even after tenure, when I started taking more risks and began wading into the policy realm, it was clear that there simply was not much space for public-facing work. Indeed, colleagues-especially senior male colleagues - at times openly questioned my commitment to "real" academic inquiry, occasionally even (subtly but painfully) mocking my work. This cultural environment directly contributed to my decision to leave my position in the Netherlands.

My move to GW drastically changed these circumstances. Located in the heart of Washington, the university actively encourages "engaged scholarship."
Traditional academic faculty work alongside practitioners; I have as many colleagues who are current or former journalists, diplomats, or policymakers as I do colleagues who fit the conventional scholar mode. One's impact on public discourse and policy agendas is valued by students, faculty, and administrators alike. At GW I am encouraged to continue my work with European policymakers and have naturally brought my data access agenda to policymakers in Washington. The more I can use my expert insights to reach beyond the ivory tower and engage wider audiences, the better.

Of course, what I have found at GW is outside the norm, even within the relatively individualistic environment of American universities. There are few institutions that embrace public-facing scholarship and policy work as actively and intentionally as GW. And to be perfectly clear, I still face significant career trade-offs. My policy work at times verges on all-consuming. I am not publishing at the rate I would like, and it may take longer for me to be promoted to full professor as a result. Yet, ultimately, I do find the trade-offs worth it. I see my knowledge and insights having tangible impacts, and that is more important to me than traditional forms of career advancement. Still, I recognize that this is a choice that I am very privileged to be able to make at all.

\subsection{Vignette 4: Katharine's Experience}

In the UK "impact" has become an embedded part of academia. Whilst not something done by all academics, a focus on "impact case studies" as part of the Research Excellence Framework assessing academic work has raised the profile of non-academic engagement. Whilst during my PhD impact was rarely discussed, as my academic career has progressed, I've been routinely encouraged through performance reviews, mentoring, and promotions processes to think about my "external standing" and impact on the world. Fortuitously, my personal research motivations align with these incentives, and I have been able to gain recognition for work that a decade ago may have gone unrecognized. However, I have also encountered a range of barriers and challenges which I've been able to challenge to different degrees.

At a practical level, as an academic based outside of London, the material costs of engagement are high. To be in London at 9 am I must be up well before dawn and spend over 3 hours traveling each way. I've been fortunate that my institution provides some funds for this kind of activity, and that some organizations have allowed me to claim expenses to cover the $f 200+$ cost of travel, but there have nevertheless been numerous occasions where I have missed out on opportunities because of cost or time factors and instances where my health and energy levels have suffered because of decisions to travel.

At a more personal level, I've also encountered challenges relating to the task of making contributions to a 
range of high profile, public, and often pressured environments. As someone who is not naturally comfortable with public speaking and who certainly does not enjoy making self-aggrandizing interventions, I've often found it difficult to have my voice heard. I have sat on many panels where I have been reluctant to "jump in" to the discussion, and I have been interrupted or spoken over more often than I care to remember. This makes it incredibly challenging to establish a reputation or exhibit the kind of authoritative voice that many audiences appear to demand.

These experiences can be deeply discouraging and have at times made me doubt the value of my engagement, but over time I have come to recognize that I am not alone in encountering these barriers and that there are sources of support. By serendipitously encountering other (often female) academics conducting this kind of work, and by subsequently consciously joining or building forums to discuss these issues, I've been able to gather advice and practical support. Whilst not overcoming all the barriers I've encountered, this community of peers has immeasurably supported my non-academic engagement.

\subsection{Reflections on the Vignettes}

These experiences highlight the range of challenges that academics can confront. Echoing existing literature, we both encountered professional and personal barriers to undertaking this work that directly undermined our ability to advocate for data access. If scholars are to be proactive, build relationships, and broker events, then time and resources are vital. But, as our vignettes show, both are exceedingly scarce. Indeed, Rebekah was only able to find the kind of support available to Katharine by switching institutions and countries. Given that this option is not available to most academics, we argue that scholars should, at the outset, consider whether institutional support is available and whether this engagement is valued. This involves asking whether you can access travel resources from your institution or via stakeholder appointments, whether there is training available, and how this activity is recognized in professional incentive structures. We have both been fortunate to find employers who value, invest in, and recognize our work, but where that is not the case, we think it is important for others to carefully consider whether they are willing to make this investment, potentially at their own personal and professional expense.

We also wish to highlight the importance of informal support. We have both benefitted from finding likeminded individuals with whom to share experiences and gain advice. Indeed, one of the best things we have done is to find and engage with one another. Proactively working to forge connections with others conducting similar work-either by personally reaching out to others already active in this space or by seeking professional associations or networks that promote pol- icy engagement-can provide tremendous personal and professional support. Whilst this of course does not eliminate the often-daunting sexist, racist, classist, and other institutional barriers, it can provide solidarity in navigating non-academic engagement. Indeed, we believe that by being aware of the potential stresses and strains before engaging, it is possible to curate a professional and personal environment that can support, rather than hinder, engagement.

\section{Discussion and Conclusion}

Drawing on our personal experiences and relating these to themes in the existing literature around non-academic engagement, in this article we have sought to explore the challenges and opportunities that academics engaging in what Bruns (2019) terms "lobbying for change" on data access and other professional issues may confront. Offering a series of vignettes that highlight different elements of our experience, we have sought to unpack the personal and structural factors that have conditioned our activity and, by reflecting on commonalities and variations in our experience, formulate advice for others interested in engaging in this area.

Reviewing our experiences, what emerges is sustained evidence that engaging with non-academic audiences is both feasible and rewarding, yet also extremely difficult and fraught with risks. Whilst we, therefore, welcome Bruns' call for more academics to engage in this activity, we also want to highlight the range of constraining factors that, in retrospect, we wish we had been aware of at the outset. At the personal level, scholars do not all come to the table with the same basic training and skillsets. Our professional backgrounds as political scientists, and Katharine's further policy training and expertise, offered advantaged starting points for this work. Whether impacting audience access or affecting the degree to which we are willing (or able) to adapt to norms of engagement, personal factors like our training-and even personal temperament-shape the opportunities and obstacles we encounter in this work. We also note the significance of structural factors at play. Whether considering academia as an institution or the dynamics of the audiences with which we seek to engage, the power structures, cultural norms, and expectations of different arenas offer both obstacles and opportunities. Indeed, we both faced significant obstacles resulting from our relatively weak networks, our gender, and our lack of elite status and prestige. At the same time, however, our status as credentialed, middle-class, white professionals afforded us standing that others would not enjoy so automatically.

Whilst no single recipe exists for engagement, our vignettes have sought to highlight ways in which it is possible for academics to exert agency-and even influence-while navigating challenging environments. First, in our discussion of data access, we reflected on the importance of proactive and creative thinking. Though 
fettered to some degree by personal and structural constraints, our experiences demonstrate the value of gaining familiarity, maintaining a presence at different types of events, and forging relationships with a variety of actors. As recognized in the existing literature on knowledge exchange, these relationships are vital to establishing both your reputation and high degrees of trust. Whilst scholars will likely encounter different barriers in building and maintaining these relationships, we advise others to persevere and invest in these kinds of activities.

Second, in reflecting on the numerous barriers we have confronted, we have considered the degree to which it is possible to exercise control. For the most part, scholars have limited ability to change the professional context in which they find themselves. But it is notable that such institutions do exist, and hence we would suggest that scholars particularly invested in this kind of work should, to the extent possible, proactively seek out employers who value this activity. There are also actions that individuals can take to try to mitigate, or at least temper, some of the personal barriers that can be confronted. Whilst it is often not possible to tackle systemic biases against certain groups of individuals, we have found informal support to be invaluable. We, therefore, advise that any academic seeking to engage in this work should strive to connect with other scholars engaged in similar activity. Whether forged through personal networks, or via professional associations, we view cultivating this kind of network to be invaluable.

In offering these reflections, we set out to provide researchers with advice on how to engage with non-academic audiences. Our reflections focus, however, on specific geographic and political contexts. Drawing in particular on our experiences with the European Commission and UK parliament we examined well-established political systems that provide numerous entry points. We also focused on contexts where platform companies have well-established resources, including staff. These dynamics are not, however, always commonplace. Different political systems focus to different degrees on expert input, whilst platforms invest much less in staffing in different parts of the world. For this reason, we recognize that our precise experiences may not translate to different political contexts. Whilst we hope that our guidance resonates in a range of settings, we recognize that academics may need to explore and develop alternative approaches to engagement.

Though focused on the issue of data access, we believe that our reflections have wider relevance for scholars interested in other topics. Our findings are likely to be of particular interest to academics who are seeking to bring about change on a topic relevant to multiple audiences, but especially policymakers and tech companies. Given the rapidly evolving nature of the internet, a range of new challenges is likely to emerge over time. Rather than acting as passive recipients of these changes, we believe that academics can play an active role in pushing for and shaping change. By demysti- fying the processes and highlighting important elements of these activities, we hope to encourage others to invest in this work.

\section{Acknowledgments}

We would like to thank the organizers and participants of the workshop on "Analyzing Citizen Engagement with European Politics through Social Media" for their invaluable feedback on the article. We would also like to thank the many individuals and organisations who have supported our efforts to engage in debates about data access, without whom this article would not have been possible. In addition, we wish to acknowledge financial support in the form of Leverhulme Project Grant RPG-2020-148 (Dommett), gifts from the Omidyar Network Fund (Tromble), and Reset (Tromble), and a grant from the John S. and James L. Knight Foundation (Tromble).

\section{Conflict of Interests}

The authors declare no conflict of interests.

\section{References}

Algorithm Watch. (2020). Operationalizing research access in platform governance: What to learn from other industries. https://algorithmwatch.org/wpcontent/uploads/2020/06/GoverningPlatforms_ IViR_study_June2020-AlgorithmWatch-2020-0624.pdf

Asbjørn Møller, L., \& Bechmann, A. (2019). Research data exchange solution. European Commission. https://ec.europa.eu/research/participants/ documents/downloadPublic?documentlds= 080166e5c7166ed8\&appld=PPGMS

Boswell, C., \& Smith, K. (2017). Rethinking policy "impact": Four models of research policy. Palgrave Communications, 3(44), 1-10.

Bruns, A. (2018). Facebook shuts the gate after the horse has bolted, and hurts real research in the process. Internet Policy Review. https://policyreview.info/ articles/news/facebook-shuts-gate-after-horse-hasbolted-and-hurts-real-research-process/786

Bruns, A. (2019). After the "APIcalypse": Social media platforms and their fight against critical scholarly research. Information, Communication \& Society, 22(11), 1544-1566.

Cairney, P., \& Oliver, K. (2020). How should academics engage in policymaking to achieve impact? Political Studies Review, 18(2), 228-244.

Chang, H. (2016). Autoethnography as method. Routledge.

Delamont, S. (2009). The only honest thing: Autoethnography, reflexivity and small crises in fieldwork. Ethnography and Education, 4(1), 51-63.

Dunleavy, P., \& Tinker, J. (2020). Maximising the impacts of academics research. Red Globe Press. 
Edelson, L., Sakhuja, S., \& McCoy, D. (2018). An analysis of Facebook's archive of ads with political content. Unpublished manuscript. https://c3media.vsos.ethz. ch/congress/2018/slides-pdf/35c3-9419explaining_ online_us_political_advertising.pdf

Ellis, C., Adams, T., \& Bochner, A. (2011). Autoethnography: An overview. Historical Social Research, 36(4), 273-290.

Farmer, R. (2010). How to influence government policy with your research: Tips from practicing political scientists in government. PS: Political Science and Politics, 43(4), 717-719.

Freelon, D. (2018). Computational research in the postAPI age. Political Communication, 35(4), 665-668.

Geddes, M. (2018). Committee hearings of the UK parliament: Who gives evidence and does this matter? Parliamentary Affairs, 71(2), 283-304.

Graffy, E. A. (1999). Enhancing policy-relevance without burning up or burning out: A strategy for scientists. In E. Kendy (Ed.), Science into policy: Water in the public realm (pp. 293-298). American Water Resources Association.

Khan, A., Din, S., \& Anwar, M. (2019). Sources and adverse effects of burnout among academic staff: A systematic review. City, 9, 350-362.

King, G., \& Persily, N. (2018). A new model for industryAcademic partnerships. PS: Political Science and Politics, 53(4), 703-709.

King, G., \& Persily, N. (2020, February 13). Unprecedented Facebook URLs dataset. Now available for academic research through Social Science One. Social Science One. https://socialscience.one/blog/ unprecedented-facebook-urls-dataset-nowavailable-research-through-social-science-one

Lomas, J. (2000). Using "linkage and exchange" to move research into policy at a Canadian foundation. Health Affairs, 19(3), 236-240.

Maynard, A. (2015). Is public engagement really career limiting? Times Higher Education. https://www. timeshighereducation.com/public-engagementreally-career-limiting
McKay, F. (2021). Dilemmas of an academic feminist as manager in the neoliberal academy: Negotiating institutional authority, oppositional knowledge and change. Political Studies, 19(1), 75-95.

Oliver, K., \& Cairney, P. (2019). The dos and don'ts of influencing policy: A systematic review of advice to academics. Palgrave Communications, 5(21), 1-11.

Perriam, J., Birkbak, A., \& Freeman, A. (2020). Digital methods in a post-API environment. International Journal of Social Research Methodology, 23(3), 277-290.

Persily, N. (2021). Opening a window into tech: The challenge and opportunity for data transparency. Stanford Cyber Policy Centre. https://fsi-live.s3.uswest-1.amazonaws.com/s3fs-public/cpcopen_windows_np_v3.pdf

Pielke, R. (2007). The honest broker: Making sense of science in policy and politics. Cambridge University Press.

Puschmann, C. (2019). An end to the wild west of social media research: A response to Axel Bruns. Information, Communication \& Society, 22(11), 1582-1589.

Tromble, R. (2021). Where have all the data gone? A critical reflection on academic digital research in the PostAPI Age. Social Media and Society, 7(1), 1-8. https:// doi.org/10.1177/2056305121988929

Vosoughi, S., Roy, D., \& Aral, S. (2018). The spread of true and false news online. Science, 359(6380), 1146-1151.

Watermeyer, R. (2015). Lost in the "third space": The impact of public engagement in higher education on academic identity, research practice and career progression. European Journal of Higher Education, 5(3), 331-347.

Weiss, C. (1979). The many meanings of research utilization. Public Administration Review, 39(5), 426-431.

Wright, J., Parry, J., \& Mathers, J. (2007). What to do about political context? Evidence synthesis, the New Deal for communities and the possibilities for evidence-based policy. Evidence and Policy, 3(2), 253-269.

\section{About the Authors}

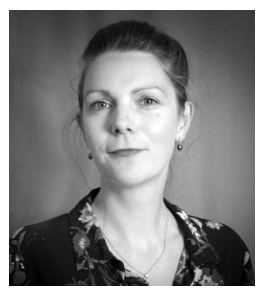

Katharine Dommett (PhD) is a senior lecturer at the University of Sheffield. Her research focuses on digital campaigning, political advertising, data, and democracy. Dommett recently served as special advisor to the House of Lords Committee on Democracy and Digital Technology. She was awarded the 2020 Richard Rose Prize by the Political Studies Association for an early-career scholar who has made a distinctive contribution to British politics. Her book, The Reimagined Party was published in 2020.

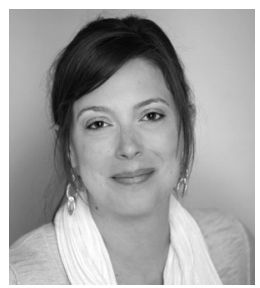

Rebekah Tromble (PhD) is an associate professor in the School of Media \& Public Affairs and is the director of the Institute for Data, Democracy \& Politics at George Washington University. Her research focuses on political communication, digital research methodology, research ethics, and online harms. Tromble consults regularly for industry and policymakers, particularly on topics of digital platform accountability, responsible data access and use, and best practices for combating the effects of disinformation. 